\title{
LIBERTAD DE EXPRESIÓN Y PROCEDIMIENTO PARLAMENTARIO: ¿ PUEDEN UNA CAMISETA, UN ADHESIVO, O UNA PANCARTA CONSTITUIR UN DISCURSO PARLAMENTARIO?
}

CARLOS FLORES JUBERÍAS 
SUMARIO

1. INTRODUCCIÓN: EN TORNO A LA RECURRENCIA Y LA RELEVANCIA DE LA EXHIBICIÓN DE MENSAJES Y SIGNOS DE CONTENIDO POLÍTICO EN EL HEMICICLO PARLAMENTARIO. 2. LOS DERECHOS EN JUEGO. 3. EL CASO DEL LEGISLATIVO VALENCIANO. 4. UNA VALORACIÓN CRÍTICA. 5. A LA ESPERA DE CONCLUSIONES, UN DEBATE ABIERTO. 


\title{
LIBERTAD DE EXPRESIÓN Y PROCEDIMIENTO PARLAMENTARIO: ¿PUEDEN UNA CAMISETA, UN ADHESIVO, O UNA PANCARTA CONSTITUIR UN DISCURSO PARLAMENTARIO?
}

\author{
CARLOS FLORES JUBERÍAS \\ Profesor titular (acreditado como Catedrático) de Derecho Constitucional, \\ Universidad de Valencia*
}

1. INTRODUCCIÓN: EN TORNO A LA RECURRENCIA Y LA RELEVANCIA DE LA EXHIBICIÓN DE MENSAJES Y SIGNOS DE CONTENIDO POLÍTICO EN EL HEMICICLO PARLAMENTARIO

En nuestros parlamentos, y en los de los países de nuestro entorno más próximo, lo usual es que los miembros de las cámaras guarden un impecable decoro en el vestir, y aun que pequen en esta cuestión de un marcado apego a las convenciones sociales más arraigadas: los trajes con camisa y corbata constituyen casi la regla entre los hombres, y los vestidos o los trajes de corte sobrio y en colores discretos son lo más habitual entre las mujeres. Atuendos más coloristas — como, por ejemplo, los que de ordinario lucen los parlamentarios indígenas de la Asamblea Legislativa Plurinacional de Bolivia- o, al contrario, blancos de pies a

* Departamento de Derecho Constitucional y Ciencia Política. Facultad de Derecho. Avenida de los Naranjos, s/n. 46071 Valencia (España).

Tel.: (34) 96382 8587. Fax: (34) 96382 8119.e-mail: carlos.flores@uv.es 
cabeza — como los que se ven entre los diputados del Lok Sabha indio- pueden ser habituales en otras latitudes, pero resultan definitivamente inimaginables en los legislativos europeos, en los que dejar de lado la corbata constituye ya de por sí un comportamiento inusual $-\mathrm{y}$, para algunos, incluso censurable.

En todo caso, sería difícil argumentar en contra de que algún miembro del parlamento decidiera romper con ese código no escrito que regula su forma de vestir. Elegir el propio atuendo constituye un derecho personalísimo, derivado de los derechos al libre desarrollo de la personalidad y a la propia imagen, que solo podría resultar limitado - tanto dentro, como fuera del parlamento- en el supuesto y en la medida en que fuera contrario a la moral o al orden público ${ }^{1}$. Por no señalar que entre los miembros del parlamento, la opción por una u otra forma de vestir - y dentro de ella, por uno u otro corte, color, tejido o forma de lucir las prendas de que se trate- podría incluso tener connotaciones de cierta trascendencia política.

Problema sustancialmente distinto, bastante más complejo, y no susceptible de resolverse mediante la simple apelación a la libertad individual de Sus Señorías para vestir como lo deseen, es en cambio el suscitado por la cada vez más extendida costumbre entre algunos parlamentarios de hacer uso de la atracción mediática habitualmente suscitan los debates en las cámaras para difundir determinados mensajes, de naturaleza normalmente política, aunque no necesariamente relacionados con los asuntos que integran el orden del día, a través de la propia indumentaria, o mediante elementos superpuestos o adheridos a ésta, o - puestos a contemplar todas las hipótesis conexas- portados por el parlamentario en sus manos al objeto de proceder a su exhibición, o colocados de manera visible por éste en su escaño.

Se trata de una práctica cada vez más frecuente y más extendida, que en algunos casos — ese es, sin duda alguna su propósito- ha alcanzado notable repercusión mediática, como cuando los diputados del Parlamento Europeo expresaron su solidaridad con el disidente chino Liu Xiaobo² o con la iraní Sakineh Mohammadi Ashtiani ${ }^{3}$ luciendo camisetas con sus nombres inscritos en ellas, o cuando

${ }^{1}$ Sobre este extremo pueden consultarse, respectivamente, MARTÍNEZ LÓPEZ-MUÑIZ, J. L. (1992) «La moralidad pública como límite de las libertades públicas», en Los derechos fundamentales y libertades públicas: XII Jornadas de Estudio, Vol. 1, Madrid, Ministerio de Justicia, pp. 1003-1021 y DE BARTOLOMÉ CENZANO, J. C. (2002) El orden público como límite al ejercicio de los derechos y libertades. Madrid, Centro de Estudios Políticos y Constitucionales.

2 «Reflections on China and the Nobel Peace Prize», CBC News de 08.12.2010 (disponible en línea en www.cbc.ca. Última consulta —en este caso, y en todos los que siguen — el 01.12.2012).

3 «European Parliament condemns Iran's stoning sentence for Ashtiani», The Times de 08.09.2010 (disponible en línea en www.thetimes.co.uk). 
los miembros del legislativo argentino se afanaron por anticipar su respaldo a la expropiación de la petrolera YPF luciendo en el hemiciclo del Congreso todo un surtido de pancartas, pasquines y adhesivos alusivos a la cuestión en la misma sesión en la que ésta iba a ser debatida y previsiblemente aprobada ${ }^{4}$. Más aun, se trata de una práctica que en determinados contextos y merced a la acción de algunos concretos grupos políticos lleva ya camino de convertirse casi en una costumbre, como sucede ya, sin ir más lejos, en el Congreso de los Diputados español, algunos de cuyos integrantes parecen haber tomado la exhibición en el hemiciclo de signos y símbolos tales como pins, tarjetas, carteles de pequeñas dimensiones, banderas, o camisetas como una forma más de expresión política, útil para expresar su oposición a la participación de España en la guerra de Iraq ${ }^{5}$ o a la intervención armada internacional en Libia ${ }^{6}$, para respaldar la convocatoria de una huelga general ${ }^{7}$, para manifestarse en contra de los recortes en materia de enseñanza ${ }^{8}$, abogar por el derecho a exhibir la bandera independentista catalana ${ }^{9}$ o, en fin, exigir el acercamiento de los presos de ETA a las cárceles vascas ${ }^{10}$.

Por regla general la tolerancia — concretada en la resignada aceptación de la exhibición de esos símbolos, a veces complementada con un cortés ruego por parte de la presidencia de la cámara para que sean retirados a la mayor brevedad posible_- ${ }^{11}$ ha sido la respuesta más habitual por parte de las autoridades encargadas de mantener el orden en los debates parlamentarios, mientras que la discreción — concretada en una exhibición puramente episódica y testimonial de

4 «Argentina: el Parlamento apura intensa jornada para aprobar ley expropiación YPF», Infolatam. Información y Análisis de América Latina de 03.05.2012 (disponible en línea en www. infolatam.com).

5 «Del "no a la guerra" al "sí a la huelga"», El Mundo de 09.09.2010 (disponible en línea en www.elmundo.es).

6 «Llamazares exhibe el "No a la guerra" y critica a Zapatero por encabezar la "coalición de París"», $A B C$ de 22.03.2011 (disponible en línea en www.abc.es).

7 «Del "no a la guerra" al "sí a la huelga"», cit.

8 «Así te contamos, minuto a minuto, la primera huelga unitaria y estatal de la Educación», 20 Minutos de 22.05.2012 (disponible en línea en www.20minutos.es).

9 «Un diputado de ERC saca la bandera estelada en la Tribuna del Congreso», $A B C$ de 13.06.2012 (disponible en línea en www.abc.es).

10 «Diputados de Amaiur exhiben en el Congreso carteles a favor del acercamiento de presos de ETA», Diario Vasco de 12.02.2014 (disponible en línea en www.diariovasco.com)

${ }^{11}$ Véase, a título de ejemplo, la posición de la Presidencia del Congreso de los Diputados en los tres últimos incidentes referidos en el párrafo anterior en Diario de Sesiones del Congreso de los Diputados n. ${ }^{\circ} 33$ (2012) de 22 de mayo, n. 38 (2012) de 12 de junio y n. ${ }^{\circ} 175$ (2014) de 12 de febrero: silencio total en el primer caso, apenas un ruego en el segundo (p. 7), y dos llamadas al orden en medio de un cierto tumulto, seguidas de la rápida recogida de los carteles en cuestión por parte de los parlamentarios que los estaban exhibiendo, en el tercero. 
los mismos, sin intención de perturbar más de lo imprescindible el desarrollo de las sesiones de la cámara - lo ha sido por parte de los parlamentarios implicados en este tipo de manifestaciones. Sin embargo, las tensiones generadas por el recurso cada vez más frecuente a estas formas de propaganda política en las reuniones del legislativo han acabado a la postre desembocando en conflicto en algunos casos que, no por puntuales, dejan de ser merecedores de consideración.

Eso fue lo sucedido en la sesión plenaria celebrada por Les Corts Valencianes el 15 de febrero de 2012, cuando una de sus diputadas resultó expulsada del hemiciclo ${ }^{12}$ por el Presidente de la cámara por estar exhibiendo una camiseta negra sobre la que de manera clara se leía el lema «No nos falta dinero. Nos sobran chorizos ${ }^{13}$, después de que ya lo hubiera sido dos años atrás por lucir

12 Nótese que la expulsión de un diputado del hemiciclo constituye una medida auténticamente excepcional en la práctica parlamentaria española. Contemplada en los artículos 104 y 105 del Reglamento del Congreso, la medida solo ha sido aplicada una vez en las nueve legislaturas transcurridas desde la aprobación de la Constitución española: concretamente en mayo de 2006, cuando el entonces presidente del Congreso Manuel Marín ordenó la expulsión del diputado popular Martínez Pujalte por interrumpir reiteradamente al orador en el uso de la palabra («Marín expulsa al diputado Martínez Pujalte del Congreso por increpar al ministro Alonso», en El País de 11.05.2006, y «Martínez Pujalte: 'Fui expulsado por solidarizarme con lo dos detenidos militantes del PP'», El País de 16.05.2012, disponibles en línea en www.elpais.es). Sin perjuicio de ello, cabe notar que a lo largo de la primera mitad de la X Legislatura han sido ya ocho los parlamentarios privados del uso de la palabra expulsados de la tribuna de oradores (aunque no de la cámara) en aplicación del 104: en concreto, tres (pertenecientes a Esquerra Republicana de Catalunya) del Grupo Mixto en la sesión del 12 de abril de 2013, cuatro del Grupo «Izquierda Plural» en la sesión del 24 de septiembre de 2013, y de nuevo uno de Esquerra Republicana de Catalunya en la sesión del 17 de septiembre de 2013 (véase «Expulsados tres diputados de ERC por realizar sus intervenciones en catalán», $A B C$ de 12.04.2013, «El diputado Bosch, expulsado de la tribuna del Congreso por hablar en inglés», Mediterráneo de 17.09.2013 y «Rebelión en el Congreso ante el veto del PP a debatir sobre Bárcenas y Rajoy», El País de 24.09.2013).

En cuanto a los parlamentos autonómicos españoles, en cuyos reglamentos la medida figura también recogida sin excepción, su uso ha sido sumamente infrecuente. En el valenciano — por lo que se ve uno de los más conflictivos_-, solo han sido expulsados del pleno seis diputados —una de ellas, dos veces - en treinta años de vida parlamentaria: Manuel Campillos (de Unión Valenciana), durante la primera legislatura de Les Corts; Manuel Ortuño (PP), durante la tercera; Eduardo Vicente (PSPVPSOE) el 23.11.2006; Mónica Oltra (Compromís) el 07.05.2009 y el 15.02.2012; Ángel Luna (PSPV-PSOE) el 24.02.2010; y Mireia Mollà (Compromís) el 12.07.2012. Véase «El ‘hooligan’ de Les Corts», Las Provincias de 26.11.2006 (disponible en línea en www.lasprovincias.es), «La presidencia de las Cortes expulsa a Luna y le excluye del debate de hoy con Camps», Información de 25.02.2010 (disponible en línea en www.diarioinformacion.com) y «Expulsión de Mollà de las Cortes por llamar mentiroso al consejero Castellano», El País de 12.07.2012 (disponible en línea en www.elpais.es).

13 Véase «La oposición abandona las Cortes al expulsar Cotino a Mònica Oltra», El País (edición Comunidad Valenciana) de 15.02.2012 (disponible en línea en www.elpais.es); «Oltra, expulsada por otra camiseta», Levante-EMV de 15.02.2012 (disponible en línea en www. levante-emv.com). 
en semejante ocasión otra prenda similar en la que bajo el lema «Wanted ( Se busca») y en un estilo que recordaba a los pasquines utilizados en el lejano oeste para la captura de forajidos, se reproducía el rostro del entonces Presidente de la Generalitat Valenciana ${ }^{14}$, y después de que en el entretanto la referida diputada hubiera venido haciendo gala de un interminable muestrario de camisetas - en un caso exigiendo transparencia al Gobierno autonómico, en otro exigiendo responsabilidades a su Presidente por el trágico accidente del metro valenciano de julio de 2006, y en otro simplemente abogando por ser felices todos los días_ ${ }^{15}$ que la habían hecho objeto de un amplio seguimiento mediático y de un sinfín de comentarios de todo cariz. Y eso fue, asimismo, lo sucedido el pasado 14 de junio de 2012, cuando siete de los ocho diputados del Partido Nacional Democrático (NPD) en el Landtag de Sajonia fueron expulsados del plenario por hallarse vistiendo camisetas de la marca «Thor Steinar» — conocida por su uso de símbolos y motivos nórdicos, y al parecer predilecta de ciertos grupos neonazis ${ }^{16}$.

La proliferación de estos incidentes en nuestros legislativos es, pues, un hecho. Como lo es también la aplicación a los mismos de medidas de muy distinto rigor, reveladoras de la inexistencia de un criterio único, claro y fiable acerca de cuáles sean los límites — si es que debe haberlos- de este tipo de acciones, y la inexistencia hasta la fecha de una reflexión profunda acerca de su naturaleza y significado, y de cual debería ser su lugar — si es que meritan tenerlo- en la vida parlamentaria. Todo lo cual hace que resulte oportuno empezar a plantearse qué valoración jurídica debería merecer este tipo de manifestaciones, y cual debería ser la respuesta que el Derecho — en este caso, el Derecho parlamentario_- diera a las mismas.

\section{LOS DERECHOS EN JUEGO}

De entrada, conviene dejar claro que el problema jurídico que plantea la exhibición de mensajes de contenido político en la propia indumentaria, o mediante

14 Véase «La portavoz de Compromís revienta el pleno con una camiseta de «se busca vivo» a Camps», Las Provincias de 07.05.2009 (disponible en línea en www.lasprovincias.es); y «Oltra, expulsada de las Corts por su camiseta de 'Se busca' a Camps», en Levante-EMV de 07.05.2009 (disponible en línea en www. levante-emv.com).

15 Véase «Galería: Las camisetas de Mónica Oltra», Levante-EMV (disponible en línea en www. levante-emv.com) y «Mónica Oltra y sus camisetas protesta» en Las Provincias (disponible en línea en www. lasprovincias.es).

16 Véase «Sächsischer Landtag: NPD-Abgeordnete sorgen mit Thor-Steinar-Kleidung für Ekla», Der Spiegel de 13.06.2012 (disponible en línea en www.spiegel.de). 
elementos superpuestos o adheridos a ésta, o portados al objeto de proceder a su exhibición en el transcurso de un debate parlamentario es susceptible de revestir una cierta complejidad sólo cuando quien la lleva a cabo es uno de los miembros de la propia asamblea legislativa, y no en cambio cuando éstos son exhibidos por el público que asiste a la sesión, hipótesis ésta tanto o más frecuente que la anterior.

La posibilidad de que los debates parlamentarios sean seguidos por el público desde tribunas o espacios expresamente reservados para ello en el propio recinto del parlamento es una tradición — «una de las reglas de oro del régimen representativo», la llaman Molas y Pitarch, después de citar a Bentham- ${ }^{17}$ que se remonta a los tiempos en que esa era la única manera de garantizar el principio de que las deliberaciones del parlamento debían ser públicas y no — salvo contadas excepciones - secretas. Una tradición que se mantiene a día de hoy en la práctica totalidad de los parlamentos a pesar de que el desarrollo tecnológico ha dado con formas mucho más confortables, e incluso más eficaces que la presencia física en la tribuna de invitados, para seguir el desarrollo de los debates parlamentarios, y que en nuestro caso concreto se halla garantizada incluso a nivel constitucional, desde el momento en que el art. 80 establece que «las sesiones plenarias de las Cámaras serán públicas, salvo acuerdo en contrario de cada Cámara, adoptado por mayoría absoluta o con arreglo al Reglamento» ${ }^{18}$.

Sea como sea — y dejando de argumentos demagógicos tan fáciles de enunciar como sencillos de rebatir_- está fuera de dudas que todo cuanto el ciudadano tenga que decir en el transcurso de estos debates debe hacerlo a través de sus representantes debidamente elegidos, y que en ellos el público asistente cuya representatividad, obvio es decirlo, se limita a la de sus propios puntos de vista - no cuenta con otro derecho que el de escuchar, estándole vetada toda forma de intervención u obstaculización del debate. La Constitución española, que en su artículo 23.1 reconoce el derecho de los españoles a participar en los asuntos públicos «directamente o por medio de representantes, libremente elegidos», y que en el resto de su articulado concreta — con más morosidad en un caso, y con más generosidad en el otro- las varias formas en que habrán de concretarse, y los modos en que habrán de conjugarse entre sí ambas modalida-

17 MOLAS, I. Y PITARCH, I. E. (1987) Las Cortes Generales en el sistema parlamentario de gobierno. Madrid. Tecnos. p. 107.

${ }^{18}$ Las normas de desarrollo de esta disposición, que no son otras que los Reglamentos del Congreso y del Senado, confirman la regla de la publicidad de las sesiones plenarias (en el art. 63, en el caso del Reglamento del Congreso, y en el 72 en el del Senado), establecen con minuciosidad los casos en los que cabrá exceptuar esa regla, y prescriben para las comisiones tanto el criterio de acceso restringido a los medios de comunicación social como las excepciones al mismo (en el art. 64, en el caso del Reglamento del Congreso, y en el 75 en el del Senado). 
des de participación, no contempla en lugar alguno la combinación de ambas en un mismo lugar y momento, de modo que la participación directa de los ciudadanos termina en el momento que comienza la indirecta a través de representantes, sin que quepa superposición o interferencia entre ambas. Es por ello que todos los reglamentos parlamentarios que contemplan la posibilidad de que el público asista a sus debates establecen el deber de los asistentes de guardar la debida compostura y no interferir en los trabajos de la cámara ${ }^{19}$, o dando éste por supuesto brindan a su presidente amplias facultades para mantener el orden en la tribuna de invitados ${ }^{20}$, y desalojar de ella a quienes lo perturben ${ }^{21}$, comple-

19 Ese es el caso de nuestro Senado, cuyo Reglamento determina en su art. 74 que «Las personas del público que asistan a las sesiones del Senado deberán abstenerse de realizar manifestaciones de aprobación o desaprobación. Tampoco podrán comunicarse en el salón de sesiones con ningún Senador».

20 Así, el Reglamento del Congreso de los Diputados confiere al Presidente amplios poderes de policía, encomendándole de manera genérica (artículo 105) el deber de velar «por el mantenimiento del orden en el recinto del Congreso de los Diputados y en todas sus dependencias, a cuyo efecto podrá adoptar cuantas medidas considere oportunas, poniendo incluso a disposición judicial a las personas que perturbaren aquél», prescribiendo (artículo 106) que «cualquier persona que en el recinto parlamentario, en sesión o fuera de ella y fuese o no Diputado, promoviere desorden grave con su conducta de obra o de palabra, será inmediatamente expulsado. Si se tratare de un Diputado, el Presidente le suspenderá, además, en el acto en su condición de Diputado por plazo de hasta un mes, sin perjuicio de que la Cámara, a propuesta de la Mesa y de acuerdo con lo previsto en el artículo 101, pueda ampliar o agravar la sanción», y añadiendo de manera más específica — por lo que aquí nos interesa- que corresponde al Presidente (artículo 107.1) velar en las sesiones públicas por el mantenimiento del orden de las tribunas de invitados, y (artículo 107.2) que «quienes en éstas dieran muestras de aprobación o desaprobación, perturbaren el orden o faltaren a la debida compostura, serán inmediatamente expulsados del Palacio por indicación de la Presidencia, ordenando, cuando lo estime conveniente, que los Servicios de Seguridad de la Cámara levanten las oportunas diligencias por si los actos producidos pudieran ser constitutivos de delito o falta.»

${ }^{21}$ A modo de ejemplo, y sin pretender ser exhaustivos, a lo largo de la última década han sido expulsados de la tribuna de invitados del Congreso de los Diputados sendos grupos de actores y actrices por protestar contra la intervención de España en la Guerra de Iraq (febrero de 2003); miembros de la Asociación de Víctimas de Terrorismo por increpar al presidente del Gobierno cuando éste defendía una iniciativa de su partido en favor del «proceso de paz» (06.06.2006); representantes de la campaña por la abolición de la deuda externa por desplegar una pancarta, arrojar octavillas y encadenarse a los asientos de la tribuna en protesta por la regulación de la deuda externa que se discutía en la cámara (23.06.2006); activistas pro-saharauis por gritar proclamas a favor de este territorio durante el debate de una moción de IU-ICV (02.12.2010); sindicalistas mineros por mostrar unas camisetas reivindicativas durante la intervención del ministro de Industria José Manuel Soria (13.06.2012); esposas de mineros por llamar «mentiroso» a un diputado que estaba haciendo uso de la palabra con ocasión de un debate sobre el estado de la minería en España (18.07.2012); de afectados por las llamadas «preferentes» por interrumpir en 
mentadas normalmente con disposiciones de rango inferior encaminadas a la prevención de posibles incidentes mediante el establecimiento filtros para la detección de casos problemáticos ${ }^{22}$.

Volviendo al caso de los parlamentarios, es evidente que en un régimen de libertades la exhibición mensajes a través de la propia indumentaria, o mediante elementos adheridos a ésta, fuera del hemiciclo parlamentario no solo no puede ser merecedora de ningún reproche, sino que constituye una clara manifestación del derecho al libre desarrollo de la personalidad — que la Constitución española califica nada menos que como uno de los «fundamentos del orden político y de la paz social»— y de la libertad de expresión, amén de que también podría serlo - dependiendo de cual fuera el concreto contenido de la consigna en cuestión- de los derechos igualmente fundamentales a la libertad ideológica o religiosa, a la creación literaria, artística, científica o técnica, o a la información. La semiología considera sobradamente acreditado ${ }^{23}$ que nuestra vestimenta no sólo sirve para protegernos de las inclemencias atmosféricas o para ocultar a la vista ciertas partes de nuestro cuerpo, sino también para transmitir informaciones cuidadosamente codificadas sobre quienes somos y qué posición ocupamos en la sociedad, como también que «toda esta información sobre la manera de ser, de pensar o de actuar se puede transmitir de dos maneras: de una forma no verbal, luciendo o prescindiendo de determinadas prendas (velo, gorra, minifalda...) o de una manera verbal, mediante la anotación de ciertos mensajes en la ropa de vestir» ${ }^{24}$. Mientras que el Derecho Constitucional da por hecho que el derecho a expresar y difundir libremente los pensamientos, las ideas y las opiniones debe hallarse garantizado - como bien dice el artículo 20.1 de la Constitucióntanto cuando éstas son expresadas mediante la palabra, como cuando lo son por escrito o por cualquier otro medio de reproducción, sin que además el ejercicio de estos derechos pueda restringirse mediante ningún tipo de censura previa.

El problema teórico, a la vez que práctico, radica en determinar si dichas manifestaciones son aceptables también en el ámbito parlamentario, o si por el

el uso de la palabra a un diputado popular con ocasión de un debate al respecto (11.04.2013); o defensores de la dación en pago opuestos a la posición del PP en relación con la iniciativa legislativa popular para la regulación de esta fórmula.

${ }^{22}$ Sobre las facultades disciplinarias de la presidencia de las asambleas legislativas, véase GARCÍA SORIANO, M. V. (2003) La Presidencia de las Asambleas Legislativas. Una perspectiva comparada, Valencia. Corts Valencianes, pp. 169-182.

23 Véase, por todos, AILES, R. (1993). Tú eres el mensaje. La comunicación con los demás a través de los gestos, la imagen y las palabras. Barcelona: Ediciones Paidós Ibérica; y SQUICCIARINO, N. (1990). El vestido habla: consideraciones psicosociológicas sobre la indumentaria. Madrid: Cátedra, o

${ }^{24}$ MORANT MARCO, R., "Aproximación al lenguaje de las camisetas con palabras», Signa: Revista de la Asociación Española de Semiótica, 18 (2009), pp. 345-364, en p. 346. 
contrario las especificidades de los procesos que se verifican en el seno de las cámaras representativas, y las garantías de que éstos deben estar revestidos, requieren exceptuar de alguna manera un régimen general de libertades.

Una primera aproximación a la cuestión, esencialmente intuitiva, llevaría a dar a esta pregunta una respuesta afirmativa. Siendo como es el parlamento un foro para la representación de ideas e intereses diversos, parecería un contrasentido que se les pudiera limitar dentro de la cámara el ejercicio de una forma de expresión política, como es la consistente en exhibir lemas en o sobre su vestimenta, de la que sin duda disponen fuera de ella y que debiera en sede parlamentaria alcanzar su más acabada expresión ${ }^{25}$.

Esa fue precisamente una de las dos líneas de razonamiento esgrimidas por la formación política a la que pertenecía la diputada expulsada de las Corts Valencianes en el recurso de amparo por vulneración de derechos fundamentales y libertades públicas ante el Tribunal Constitucional planteado con fecha de 15 de mayo de 2012 en respuesta a la segunda de sus expulsiones ${ }^{26}$, y que a día de hoy se halla aun pendiente de resolución. En él, se argumenta que, en casos como el presente,

«La libertad de expresión de la que gozan todos los ciudadanos adquiere un carácter todavía más esencial por el carácter de representante de la recurrente, que no sólo abarca las ideas, sino también el ámbito de cómo éstas se expresan, de modo que uniformar a los diputados equivale a cercenar parte de su derecho y deber de representación que, a nuestro juicio también se extiende a la imagen y a la manera de presentarse ante la sociedad.»

De manera que la expulsión del hemiciclo de la recurrente por exhibir una determinada leyenda en su ropa, cualquiera que fuera ésta, entrañaba una palmaria violación de derecho a la libertad de expresión consagrado en el artículo 20.1.a) de la Constitución.

La otra línea argumentativa, complementaria de la anterior — y ya esgrimida por la diputada antedicha en el recurso de reposición contra la segunda de sus expulsiones presentado ante la mesa de Les Corts al amparo de lo dispuesto en el

25 Especialmente si tenemos en cuenta, como en su día concluyó el Tribunal Constitucional, que (STC 51/1985) que la inviolabilidad parlamentaria se halla encaminada «a la preservación de un ámbito cualificado de libertad a la crítica y a la decisión sin la cual el ejercicio de las funciones parlamentarias podría resultar mediatizado y frustrado».

${ }^{26}$ Documento inédito, en posesión del autor. Véase al respecto «Compromís recurre ante el Tribunal Constitucional la expulsión de Oltra de las Corts por llevar una camiseta alusiva a la corrupción», Europa Press de 18.05.2012 (disponible en línea en www.europapress.es). 
artículo 34.2 de su reglamento——27 ${ }^{27}$, aludiría a que la expulsión de la cámara por lucir lemas o símbolos de naturaleza política en o sobre la propia ropa vulneraría el derecho de representación política del artículo 23 de la Constitución española en su doble dimensión: violando a la vez el derecho de la diputada a ejercer como tal, y el de los ciudadanos por ella representados a ver sus intereses defendidos en la cámara, puesto que

«Cuando un cargo público recaba la tutela jurisdiccional del Tribunal Constitucional no sólo está recabándola para sí mismo, sino también para los ciudadanos y ciudadanas a los que representa puesto que [...] no solo se vulnera el derecho del recurrente, sino también el de los ciudadanos y ciudadanas a los que representa, y por lo tanto la vulneración afecta a la calidad democrática de nuestro Estado de Derecho» ${ }^{28}$.

Pero es evidente que semejantes argumentos, llevados hasta sus últimas consecuencias, podrían acabar con la completa eliminación de cuantas reglas son usadas en los parlamentos para la ordenación de sus trabajos. Si cualquier norma encaminada a regular, racionalizar y ordenar un debate —o una votación-, con ocasión del desarrollo de un proceso legislativo o de control en la cámara en virtud de la cual se limitara el uso de la palabra de un parlamentario determinando durante cuánto tiempo o sobre qué asunto podía intervenir, o se

27 Véase escrito dirigido a la Mesa de Les Corts por la diputada Oltra Jarque, de fecha 20.02.2012, con Reg. Entr. Núm. 16.501, respondido por ésta declarando su inadmisibilidad mediante escrito de fecha 01.03.2012, con Reg. Sal. Núm. 06.099 (documentos inéditos, ambos en posesión del autor).

También la expulsión de mayo de 2009 fue objeto de un recurso ante la Mesa, igualmente rechazado.

${ }^{28}$ En una tercera línea argumental, el recurso de la diputada Oltra Jarque apelaría también a la violación de «los principios de legalidad, seguridad jurídica e interdicción de la arbitrariedad de los poderes públicos consagrados en el artículo 9 [de la Constitución, y] el principio de igualdad consagrado en el artículo 14 de la meritada Norma Fundamental», por entender que su expulsión del hemiciclo le había generado indefensión, toda vez que se había llevado a cabo sin permitirle el uso de la palabra, ni a ella ni al portavoz de su grupo; había sido arbitraria, toda vez que se sostenía sobre una «simple remisión al decoro de la cámara» que a falta de mayores concreciones «resulta arbitraria e injusta, dada la subjetividad con que cada uno entiende el decoro en la cámara y dado que no existen reglas o desarrollos de este concepto consensuadas sobre el mismo»; y resultaba injustificada ( «atrabiliaria», dice en su recurso) toda vez que se había verificado «cuando ya habían pasado varias horas desde que ocupase su escaño y cuando ya había subido [la diputada] en una ocasión a la tribuna para realizar una intervención con la misma vestimenta». Curiosamente, el Diari de Sessions (vid. Infra.) no recogería alusión alguna a la supuesta falta de decoro de la diputada por parte del Presidente de la cámara en el momento de su expulsión, y sí al hecho de que hasta el momento de su primera llamada al orden la diputada hubiera llevado el rótulo de su camiseta cubierto por «un chaleco o algo». 
limitara su capacidad de hacer propuestas estableciendo requisitos o plazos para su formulación, fuera susceptible de constituir una violación de su derecho a la libre expresión, y toda sanción por su incumplimiento una vulneración de su derecho a ejercer como parlamentario, habríamos de concluir en el absurdo de que el parlamento debiera operar en ausencia de toda norma de procedimiento, de modo que sus integrantes pudieran hacer uso de la palabra dónde, cuándo y por el tiempo que desearan, e incluso hacer propuestas, enmendarlas y votarlas sin sujeción a norma alguna, lo que literalmente acabaría con el parlamento como órgano legislativo y de control, y aun como foro cualificado para el debate político.

Lo insostenible de este planteamiento obliga a reconducir la cuestión, no a si las reglas generales de procedimiento que tienen por fin regular el desarrollo de los trabajos parlamentarios son aceptables o no, sino a si ésta en concreto lo es.

De manera paralela, también sería relevante a este respecto determinar si las acciones que nos hallamos analizando podrían encontrarse o no amparadas por la prerrogativa de la inviolabilidad de la que gozan nuestros parlamentarios, y que — como es sabido — ${ }^{29}$ tiene por objeto protegerles de toda sanción por las opiniones expresadas y los votos emitidos en el ejercicio de su función representativa.

Para brindar una respuesta concluyente a esa pregunta sería preciso comprobar antes si las acciones que nos hallamos analizando serían o no susceptibles de incardinarse en los marcos temporal, material y funcional que definen la vigencia de la prerrogativa de la inviolabilidad ${ }^{30}$. Si el primer referente -el temporal - no plantea problemas desde el momento en el que la exhibición de mensajes a través de la propia indumentaria, o mediante elementos adheridos a ésta, en el hemiciclo parlamentario solo se podría producir siendo miembro de la cámara, y el segundo —el material — tampoco parece especialmente difícil de verificar, ya que el concepto de opinión al que hacen referencia tanto el artículo 71 de la Constitución, como el 10 del Reglamento del Congreso y el 21 del del Senado cubriría por su amplitud la exhibición de cualquier lema, signo, o

29 Sobre el concepto de inviolabilidad parlamentaria y su alcance, véase entre la ingente literatura al respecto, FERNÁNDEZ-VIAGAS BARTOLOMÉ, P. (1990). La inviolabilidad e inmunidad de los Diputados y Senadores: la crisis de los «privilegios» parlamentarios, Madrid, Civitas; ABELLÁN, Á. M. (1992). El estatuto de los parlamentarios y los derechos fundamentales, Madrid, Tecnos; SORIANO HERNÁNDEZ, E. (2001). El estatuto de los parlamentarios de las comunidades autónomas, Madrid, Senado: Departamento de Publicaciones; CATALÀ I BAS, A. H. (2006). El futuro ¿incierto? de las prerrogativas parlamentarias, Valencia, Corts Valencianes; y MANCISIDOR ARTARAZ, E. (2009). La prerrogativa constitucional de la inviolabilidad parlamentaria, Vitoria, Instituto Vasco de Administración Pública.

${ }^{30}$ CATALÀ I BAS, A. H. (2006). El futuro ¿incierto? de las prerrogativas parlamentarias, cit., pp. 50 y ss. 
símbolo —incluso de los más odiosos_ - que los parlamentarios pudieran llevar o exhibir en el hemiciclo, el tercero — que alude a la dimensión funcional de la inviolabilidad parlamentaria- plantea en cambio las suficientes dudas como para que a la postre proceda concluir que la exhibición de mensajes a través de la propia indumentaria, o mediante elementos adheridos a ésta por parte de los parlamentarios no debería estar protegida por el privilegio de la inmunidad.

La clave de la cuestión radica en que la interrelación que el artículo 71.1 de la Constitución - y, a partir de él, las disposiciones que lo desarrollan en los diversos reglamentos parlamentarios - exige que exista entre la expresión de opiniones por parte de los parlamentarios y el ejercicio por parte de éstos «de sus funciones» obliga a asumir que solo lo estarán aquellas manifestaciones que tengan una relación directa con el desempeño de las tareas propias del parlamentario o, como precisa Fernández-Viagas, que se produzcan «en el ejercicio de los instrumentos (orales y escritos) previstos por los reglamentos de las cámaras para dar cauce al ejercicio de las funciones propias del parlamentario» ${ }^{31}$, parecer éste que la jurisprudencia constitucional asumió de manera plena ya en su STC 51/1985, de 10 de abril. Y resulta harto dudoso que la exhibición de lemas, signos, o símbolos por parte de un parlamentario cuando éste no se hallara en el uso de la palabra, o carecieran de conexión con los asuntos que estuvieran siendo tratados en la cámara, o tuvieran por objeto mismo interrumpir o perturbar el normal funcionamiento de ésta puedan acabar incardinados en la cláusula que circunscribe al ejercicio de las funciones propias del parlamentario el ámbito de protección de la inviolabilidad. Y es que, como concluye Català i Bas, «no todo ejercicio de la libertad de expresión está protegido por esta prerrogativa» ${ }^{32}$.

\section{EL CASO DEL LEGISLATIVO VALENCIANO}

Como ya se ha apuntado, en los dos casos que acabamos de referir, la Presidencia de Les Corts Valencianes apartándose de la práctica más habitual en éstos y en similares casos, optó por apercibir primero, y expulsar después a la diputada en cuestión del hemiciclo, prohibiéndole la asistencia al resto de la sesión, y amparó su decisión ${ }^{33}$ en la facultad que le confería el reglamento la cámara para

31 FERNÁNDEZ-VIAGAS BARTOLOMÉ, P. (1990). La inviolabilidad e inmunidad de los Diputados y Senadores..., cit., p. 53.

32 CATALÀ I BAS, A. H. (2006). El futuro ¿incierto? de las prerrogativas parlamentarias, cit., p. 59.

33 Corts Valencianes: Diari de Sessions núms. 82/VII, de 07.05.2009, pp. 2.809-2.810 y 27/VIII, de 15.02.2012, p. 923. 
mantener el orden en el seno de la misma, facultad contemplada en los artículos 103 y 104 del Reglamento de Les Corts Valencianes ${ }^{34}$. Pero ello con una interesante diferencia: y es que mientras en el primero de los casos, la Presidenta de Les Corts señaló a la diputada en cuestión que la imagen y el rótulo contenido en su camiseta era ofensivo para la primer autoridad de la Generalitat Valenciana, en el segundo el Presidente de la cámara se abstuvo de indicarle en cual de las cuatro hipótesis sancionables del artículo 103 del Reglamento estaba incardinando su acción. Y con posterioridad al incidente, inseguro quizás de que su decisión tuviera sustento reglamentario suficiente, o al objeto de evitar en el futuro situaciones similares y brindar tanto a los parlamentarios como a los funcionarios de la cámara un criterio más firme al que acogerse, con fecha de 17 de abril de 2012 emitió una Resolución de carácter general ${ }^{35}$ amparada esta vez en lo dispuesto por el artículo 31.2 del Reglamento de la cámara ${ }^{36}$ para, entre otras cosas, regular esta cuestión.

En concreto, el Capítulo III de la citada resolución estableció que

«La Presidencia de Les Corts y, en su caso, de las diferentes comisiones, velarán para que los diputados presentes en el hemiciclo o en las salas de comisión respeten las reglas de orden, establecidas en el artículo 98 del RC y, en este sentido, deberán actuar de inmediato cuando se utilicen prendas de vestir, carteles, fotografías, pancartas u otros elementos materiales que pudieran resultar alusivos a algún diputado, institución o terceras personas, o cuando de algún otro modo se menoscabe el decoro de la cámara, en cuyo caso, sin perjuicio de aquello que establece el RC, procederán a su expulsión y a la adopción, si procede, de las medidas sancionadoras y disciplinarias que correspondan de acuerdo con los artículos 88 a 107 RC.»

34 Corts Valencianes: «Reglamento de Les Corts Valencianes, aprobado por el Pleno de Les Corts el 18 de diciembre de 2006», BOE núm. 161, de 06.07.2007, pp. 29.172 y ss.

35 «Resolución de Presidencia de carácter general [núm. I/VIII] sobre la utilización de las salas institucionales, espacios y otras dependencias de Les Corts, así como del acceso y permanencia del público a zonas autorizadas de los edificios del recinto parlamentario, así como de otros aspectos referidos a sesiones del Pleno y de comisión», Butlletí Oficial de Les Corts Valencianes núm. 68, de 20.04.2012, pp. 8.656-8.661.

36 Nótese que el citado artículo exige para la adopción de estas resoluciones de Presidencia el parecer favorable de la Mesa y de la Junta de Síndics, que en este caso fueron obtenidos — por mayoría - en sendas reuniones de 17 de abril de 2012.

Y nótese igualmente que las citadas «Resoluciones de Presidencia de carácter general» son normas dictadas — con las limitaciones antedichas — por la Presidencia de la cámara al objeto de dar interpretación en caso de duda, o de suplir en caso de silencio, las disposiciones recogidas en el Reglamento de la cámara, siempre dentro de los límites marcados por el propio Reglamento y el Estatuto de Autonomía y de los derivados de la susceptibilidad de recurrirlas en amparo ante el tribunal Constitucional (Vid. STC 44/1995). 
A modo de complemento de la anterior, otros apartados de la resolución extenderían la misma prohibición a cualesquiera otras dependencias o espacios de Les Corts (apartado 2), establecerían la obligación por parte de los servicios de seguridad de la cámara de impedir el acceso al recinto de quienes portasen alguno de los citados elementos (apartado 1 in fine), prohibiría y sancionaría con la expulsión de la cámara la realización de gestos de aprobación o reprobación desde las tribunas destinadas al público (apartado 2), y permitiría la adopción de medidas preventivas tales como la prohibición de que accedan a la tribuna de público e invitados e incluso al propio recinto parlamentario en su conjunto de aquellas personas con antecedentes por el incumplimiento de esas normas (apartado 2 in fine), y la retirada a los grupos parlamentarios, por el tiempo que la Presidencia estime oportuna, del derecho a extender invitaciones para asistir a las sesiones de la cámara en los casos en los que los invitados de ese grupo parlamentario hubieren perturbado el orden de los trabajos de la cámara de manera reiterada (apartado 3).

A nuestro juicio, aunque la Resolución de Presidencia ${ }^{37}$ resulte indudablemente útil de cara a la evitación de situaciones semejantes en el futuro y a la asunción de ciertas normas de comportamiento tanto por parte de los diputados y de los grupos parlamentarios, como del público que habitualmente asiste a las sesiones de la cámara ${ }^{38}$, la misma no resultaba imprescindible para justificar

37 Sobre la naturaleza, alcance, valor y recurribilidad de este tipo de resoluciones, véase GARCÍA SORIANO, M. V. (2003) La Presidencia de las Asambleas Legislativas..., cit., pp. 190-194

${ }^{38}$ Muy distinto sería, en cambio, el parecer de los grupos de oposición en el legislativo valenciano. Izquierda Unida se declararía «insumiso ante este Reglamento» (sic), anunciaría un recurso ante el Tribunal Constitucional del que a la postre desistiría, y promovería la solicitud, respaldada por los restantes grupos de oposición, de «un informe de legalidad del reglamento» (sic) por parte de los letrados de la cámara valenciana («EU llevará al Constitucional el reglamento anti-camisetas de Cotino», Las Provincias de 17.04.2012, en línea en www. lasprovincias.es).

Por parte de la Mesa de la cámara (véase escrito dirigido a la Sra. Sanz Alonso por la Secretaria Primera de Les Corts, de fecha 31.05.2012, con Reg. Sal. Núm. 09.164. documento inédito en posesión del autor) se informó a la coalición de que el citado informe había sido ya emitido a petición de la propia Presidencia de la cámara, aunque con posterioridad a la publicación de la Resolución en cuestión. El citado informe básicamente confirma la facultad del Presidente de la cámara para emitir resoluciones de carácter general; puntualiza su naturaleza, alcance y fiscalización; sostiene la regularidad formal de su adopción en este caso concreto; desglosa con minuciosidad su contenido; puntualiza la dimensión ora interpretativa, ora supletoria del sus disposiciones; confirma su recurribilidad ante el Tribunal Constitucional ...y a la postre concluye sin entrar en la constitucionalidad de su contenido ni posicionarse en modo alguno sobre la posible existencia de una vulneración de derechos, toda vez que «no procede en un informe como éste adentrarse en contenidos concretos [...] sino confirmar que efectivamente el procedimiento seguido para su 
ex post facto las expulsiones de la diputada que con su indumentaria había suscitado la cuestión, amen de que — como es obvio - una resolución de este tipo posterior en el tiempo a los hechos jamás podría ser objeto de una aplicación retroactiva. Y ello porque el Reglamento de Les Corts ya habilitaba a la Presidencia de la cámara a tomar una medida como la que tomó, por más que en su articulado no se contuviera una referencia expresa, sino genérica, a la situación que la desencadenó.

En efecto el Reglamento de Les Corts Valencianes establece en su artículo 98 que

«durante las sesiones de Pleno y de comisión, los diputados y diputadas tienen la obligación de respetar las reglas del orden establecidas por este reglamento; de evitar toda clase de perturbaciones o desorden, acusaciones o recriminaciones entre ellos, expresiones inconvenientes al decoro de la cámara, interrupciones a los oradores sin autorización de la Presidencia, y hacer uso de la palabra más tiempo de lo autorizado, como también entorpecer deliberadamente el curso de los debates y de las votaciones o de obstruir el trabajo parlamentario.»

En consecuencia, el referido artículo 103 del Reglamento establece que los diputados, las diputadas y los oradores serán llamados al orden por quien en cada momento presida la sesión del pleno de la cámara, de sus comisiones, o de cualquier otro órgano de ésta:

«1. Cuando profirieren palabras o vertieren conceptos ofensivos al decoro de la cámara o a sus miembros, de las instituciones de La Generalitat o del Estado, o de cualquier otra persona o entidad.

2. Cuando en sus discursos faltaren a lo establecido para la buena marcha de las deliberaciones.

3. Cuando con interrupciones o de cualquier otra forma alteraren el orden de las sesiones.

4. Cuando retirada la palabra a un orador, pretendiere continuar haciendo uso de ella.»

\section{Añadiendo el artículo 104 que}

«1. Al diputado o diputada u orador que hubiere sido llamado al orden tres veces en una misma sesión, advertido la segunda vez de las consecuencias de una

aprobación ha sido el establecido». Véase «Informe de los Servicios Jurídicos en relación con el cumplimiento del artículo 31.2 del Reglamento de las Cortes Valencianas (RCV) con relación a la aprobación de las resoluciones de carácter general 1/VIII y 2/VIII», (documento inédito en posesión del autor). 
tercera llamada, le será retirada, en su caso, la palabra, y la Presidencia, sin debate, le podrá imponer la sanción de no asistir al resto de la sesión.

2. Si el diputado o diputada sancionado no atendiere el requerimiento de abandonar el salón, la Presidencia adoptará las medidas que considere pertinentes para hacer efectiva la expulsión. En este caso, la Presidencia, sin perjuicio de lo establecido en el artículo 101.1.3. ${ }^{\circ}$ podrá imponerle además la prohibición de asistir a la siguiente sesión.

3. Cuando se produjera el supuesto previsto en el punto $1 .^{\circ}$ del artículo anterior, la Presidencia requerirá al diputado o diputada y orador para que se retiren las ofensas proferidas y ordenará que no conste en el Diario de Sesiones. La negativa a este requerimiento podrá dar lugar a sucesivas llamadas al orden, con los efectos previstos en los apartados anteriores de este artículo.

4. El contenido de los artículos 101, 102 y 103 será de aplicación tanto en las sesiones de Pleno como de comisión, así como en las de cualquier otro órgano de la cámara ${ }^{39}$.

\section{UNA VALORACIÓN CRÍTICA}

Desde nuestro punto de vista, el acto de presentarse en el hemiciclo de la cámara en el transcurso de un debate parlamentario portando un mensaje de contenido político bien impreso en la ropa que se esté vistiendo (caso de las camisetas de la referida diputada de Les Corts Valencianes, y de otros varios parlamentarios del Congreso), bien prendido en ésta en forma de adhesivo o tarjeta (caso de las famosas pegatinas contra la guerra de Iraq, o contra los desahucios, o contra los recortes), bien sosteniéndolo en las manos en forma de cartel o pancarta (como en tantas ocasiones han hecho los parlamentarios de la Izquierda Plural, Esquerra Republicana o Amaiur en el Congreso), bien colocándolo en lugar visible en el propio escaño o en cualquier otro lugar del hemiciclo, está llamado a constituir — en función de lo ostentosa que fuera su exhibición—, una acción susceptible de generar desorden en la cámara y de perturbar el desarrollo del debate que se esté produciendo (la hipótesis contemplada en el artículo 103.3 del reglamento del Congreso, y en la disposición de idéntico número del de Les

39 Nótese que la regulación del tema en el Reglamento de Les Corts Valencianes es tan idéntica a la del Reglamento del Congreso de los Diputados... que incluso coincide en la numeración de los artículos correspondientes. 
Corts Valencianes) y, por lo tanto, merecedora de una llamada al orden por parte de quien esté a cargo precisamente del mantenimiento de ese orden y, eventualmente, de una sanción en el caso de que la llamada al orden fuera desoída. Y ello en el mejor de los casos, dado que en función del concreto contenido del mensaje, su lucimiento podría resultar también ofensivo para otros parlamentarios, o para la cámara en su conjunto, o para otras instituciones del Estado o la comunidad autónoma ${ }^{40}$, o constituir una expresión contraria al decoro de la cámara —hipótesis todas ellas contempladas en el 103.1 de los dos textos normativos antecitados.

Por si eso no bastase, y sin necesidad —estimamos- de hacer complejas cábalas, podría incluso argumentarse que la exhibición de un mensaje de contenido político por cualquiera de los medios antes apuntados por parte de un parlamentario presente en la cámara constituiría un caso análogo al de hacer uso de la palabra por más tiempo de lo autorizado por las normas de procedimiento de la cámara (la hipótesis contemplada en el artículo 103.4 de los dos textos normativos antecitados), ya que al fin y al cabo la exhibición pública de un lema a los efectos de que sea leído por los demás miembros de la cámara, el público asistente y —no lo olvidemos, ya que seguramente esos serán sus principales destinatarios - los medios de comunicación que se hallen cubriendo informativamente el debate, equivale a la emisión continuada de un discurso, por breve y elemental que este sea, al margen de la regular distribución de los turnos de palabra.

En última instancia, se trataría de una acción carente por completo de sustento en ninguno de los derechos que los Reglamentos del Congreso y del Senado —así como de Les Corts_ otorga expresamente a sus diputados, potencialmente dañina para algunos de éstos, y difícilmente compatible con algunos de los deberes recogidos en estos Reglamentos. En efecto, el Reglamento del legislativo valenciano reconoce a los diputados (artículo 11.1) «el derecho de asistir con voz y voto» - pero no el de hacerlo provistos de ningún otro medio de acción_ —a las sesiones del Pleno de Les Corts y a las de las comisiones a que pertenezcan y a ejercer las facultades y desempeñar las funciones que este regla-

40 Esta sería precisamente la hipótesis aplicada en la ya mencionada expulsión de la misma diputada en la sesión del 7 de mayo de 2009, toda vez que el Presidente de la Generalitat Valenciana es necesariamente miembro de Les Corts. La Presidenta de la cámara optó en aquella ocasión primero por interrumpir el debate en curso para rogar a la diputada que depusiera su actitud, después por suspender la sesión durante cinco minutos y llamar a consultas a los portavoces de los grupos, y en última instancia por llamar al orden a la diputada y acabar expulsándola tras la tercera llamada por entender que la referida camiseta entrañaba una ofensa a la primera institución de La Generalitat. Vid. Corts Valencianes: Diari de Sessions núm. 82/VII, de 07.05.2009, cit. supra. 
mento les atribuye» —entre las que obviamente no se encuentra recogida la de hacer ostentación en las citadas sesiones de símbolos o lemas. Ordena (artículo 19) que estarán «obligados a observar la cortesía debida y a respetar las normas establecidas en este reglamento para el buen orden y la disciplina parlamentaria», deberes ambos abiertamente incompatibles con la exhibición de determinadas consignas. Y establece (artículo 68.1) que ninguno de ellos «podrá hacer uso de la palabra sin solicitarla y obtener la autorización de la Presidencia», y que (artículo 68.2) «los discursos se pronunciarán personalmente y de viva voz» —exigencias ambas difícilmente cohonestables con la posibilidad de deambular por el hemiciclo exhibiendo consignas políticas en o sobre la vestimenta que se esté portando. $\mathrm{Y}$ el del Congreso regula la cuestión en similares términos en sus artículos $16,70,71$ y 73 .

Adicionalmente, la posibilidad de que en el transcurso de un debate parlamentario la palabra hablada sea sustituida por la palabra impresa sobre cualquiera de los medios — camisetas, adhesivos, tarjetas, pasquines o pancartas - a los que nos estamos refiriendo provocaría en el diputado o en grupo parlamentario afectados la indefensión resultante de la imposibilidad de solicitar los correspondientes turnos por alusiones o de réplica que el Reglamento del Congreso contempla en sus artículo 71 (y el de Les Corts en sus artículos 69 y $71-$. Salvo, naturalmente, que el Presidente de la cámara considerara que una camiseta, un adhesivo, una tarjeta, un pasquín o una pancarta exhibida en el hemiciclo puede en efecto constituir un discurso, estimara que a través de ellos se había deslizado un juicio de valor o una inexactitud sobre la persona o conducta de un diputado, o que hubiera quedado afectado el decoro o dignidad de un grupo, o que se hubiera barajado un argumento que meritase replica o rectificación, y se atreviera a concederle la palabra al diputado o al grupo afectado — solución ésta que solo cabría calificar de kafkiana.

Es por ello que no cabe sino una valoración favorable de las dos decisiones de la Presidencia de la cámara valenciana de expulsar del hemiciclo a la diputada en cuestión en los dos casos referidos, en tanto que en ambos su comportamiento se hallaba plenamente incardinado en la hipótesis del artículo 98, y el del Presidente en las de los artículos 103 y 104 del reglamente de Les Corts ${ }^{41}$.

41 Restaría por dilucidar, si acaso, la cuestión de si en su concreta materialización se le pudo generar a la diputada expulsada algún tipo de indefensión. La tesis de que así fue — sostenida por ésta en su recurso de amparo contra la expulsión del 15.02.2012 y justificadora en parte del mismo- - se apoya en el hecho de que el Presidente de la cámara no tuvo a bien explicar a la diputada cual era la precisa apoyatura reglamentaria sobre la cual estaba sosteniendo sus sucesivas llamadas al orden, y que en el transcurso del incidente no se le concedió la palabra ni a ella, ni al Síndic (portavoz) de su grupo parlamentario. Si la primera objeción queda en buena parte desmentida 
Esa valoración, sin embargo, debe ser poderosamente matizada en lo que respecta a la ya mencionada Resolución de Presidencia de 17 de abril de 2012. En efecto, las menciones que en ella se realizan al buen nombre o la imagen de diputados, instituciones o terceras personas, y al decoro de la cámara como bienes jurídicos protegibles frente a la exhibición de prendas de vestir, carteles, fotografías, pancartas u otros elementos materiales que pudieran menoscabarlos no son inadecuadas, pero son en exceso reduccionistas, yerran en la identificación del bien jurídico a proteger, y parecen como motivadas por el que algunos ya habían definido jocosamente como «el fondo de armario» de la diputada reiteradamente sancionada ${ }^{42}$. Ciertamente, el objeto de los lemas contenidos en camisetas, carteles, fotografías o pancartas es susceptible de ser - y con frecuencia había sido en Les Corts Valencianes - el menoscabo de la honra de diputados o instituciones, y ciertamente también, la exhibición de alguno de ellos podría menoscabar el decoro exigible a los parlamentarios. Pero la razón de su prohibición no debería ser tanto esa, como su potencial perturbador para los trabajos de la cámara, derivado por un lado de su contenido político y por otro de su ostentación en el transcurso de estos trabajos.

Este otro enfoque permitiría proscribir no solo la exhibición de lemas o símbolos ofensivos para el buen nombre o la imagen de diputados, instituciones

por el hecho de que el Presidente apelara a la leyenda de su camiseta como el motivo para las sucesivas llamadas al orden - por más que, en efecto, no precisara si consideraba su exhibición como atentatoria contra el decoro de la cámara, o contra el orden en los debates- la segunda queda palmariamente desmentida por la interpretación que hasta la fecha ha venido haciendo el Tribunal Constitucional español de las facultades reglamentariamente atribuidas a los presidentes de los órganos legislativos para el mantenimiento del orden en el transcurso de sus trabajos. En efecto, ya en su STC 136/1989 (fto. jco. 3..$^{\circ}$ el alto Tribunal sostuvo que dichas facultades reglamentarias «habilita[n] al Presidente de los medios de represión inmediata, de plano, de los causantes de desórdenes graves. Las sanciones que en tales supuestos se alteración puede imponer el Presidente se justifican exclusivamente, dada su excepcionalidad, en razón del fin mencionado, y son por ello inescindibles del momento en que la perturbación tiene lugar». Por ese motivo - $y$ en este caso, según la STC 301/2005, de 21 de noviembre- la exigencia de un trámite previo de audiencia por parte del diputado afectado, siquiera en la forma de un simple turno de palabra, que en buena lógica podría suscitar la petición de ulteriores turnos por otros parlamentarios, «desconocería la naturaleza de las sanciones que, como la que nos ocupa, puede imponer el Presidente de un colegio con la finalidad de garantizar el orden preciso para su correcto funcionamiento, así como comportaría unas consecuencias incompatibles con nuestra doctrina».

La indefensión, en todo caso, quedaría matizada por la susceptibilidad de recurrir en amparo la citada decisión, toda vez que al constituir un acto parlamentario firme, pero sin valor de ley, se encuentra incardinado en las hipótesis contempladas por el artículo 42 de la LO 2/1979, del Tribunal Constitucional como justificadores del amparo.

42 ESTEBAN, H., «Miss camiseta mojada», El francotirador de 15.04.2012 (en línea en http:// blogs.lasprovincias.es/elfrancotirador). 
o terceras personas, o contrarios al decoro de la cámara, sino también el de aquellos que, aunque fueran perfectamente respetuosos con personas o instituciones, pudieran por causa de su contenido político generar controversia entre los parlamentarios, incomodar a quien estuviera en el uso de la palabra, o sencillamente distraer la atención de quienes deberían tener esta enteramente focalizada en el orden de día de la sesión, al tiempo que en cambio permitiría la exhibición de otros — por ejemplo, de marcas comerciales o similares- que carecieran de todo potencial perturbador ${ }^{43}$.

Este punto de vista obligaría asimismo a concluir —en contradicción esta vez con lo dispuesto en la nueva normativa valenciana- que la exhibición de estos lemas o símbolos debería ser prohibida — - y, de producirse, ser castigadaúnicamente cuando se produjera con ocasión de la reunión de un órgano parlamentario, como pudiera ser el plenario, pero también cualquiera de sus comisiones, su mesa, o incluso de sus grupos parlamentarios, pero no en cambio cuando se verificara sin más dentro de las dependencias de la cámara, y mucho menos en sus accesos o aledaños. Si es fácil de entrever el potencial perturbador de la exhibición de estos signos sobre el trabajos de los órganos colegiados de la cámara cuando éstos se hallaren reunidos, no se adivina cual pudiera ser el inconvenien-

43 Nótese que en otras dos ocasiones al menos, la referida diputada trató de poner a prueba los límites de la nueva política de la Presidencia de Les Corts Valencianes, sin que en ninguno de los dos casos se considerase necesario por parte de ésta adoptar medida sancionadora alguna. A la semana siguiente de su segunda expulsión, la diputada Oltra Jarque lució una camiseta con un Código QR impreso a la altura del pecho («Una diputada burla la normativa con una camiseta en código QR contra la brutalidad policial en Valencia», en ABC-Comunidad Valenciana de 22.02.2012, disponible en línea en www.abc.es), mientras que en la primera sesión celebrada tras la publicación de la referida Resolución de la Presidencia exhibió una prenda con el logo de la conocida marca «Mango» - término que, como es sabido, en lenguaje vulgar es sinónimo de «robo»- en lugar bien visible mientras se debatía en comisión en torno a la desaparición de 25 millones de euros en la gestión de una depuradora de aguas ( «Mónica Oltra luce camiseta 'Mango' en la comisión sobre el saqueo de Emarsa,», El Mundo-Comunidad Valenciana de 18.04.2012, disponible en línea en www.elmundo.es). Es de suponer que la Presidencia entendió en el primer caso que dado que los Códigos QR no son descifrables sino mediante el uso de un smartphone, no había lugar a entender que pudiera perturbar el desarrollo de la sesión, y que en el segundo caso optó por hacer una interpretación pro libertate de las intenciones de la diputada, y entender que «Mango» era una marca comercial y nada más que eso.

Punto de vista este último diametralmente opuesto al adoptado por el Presidente del Landtag de Sajonia, quien en el incidente antes referido (vid. supra nota 14) entendió que la asociación entre la marca «Thor Steinar» y los grupos neonazis que la usan de manera habitual convertía la exhibición organizada de tales prendas en una manifestación de indudable carácter político, prohibida por el reglamento de la cámara, por más que el propietario de la marca hubiera reiterado en numerosas ocasiones el carácter no político de su empresa, y que en las camisetas lucidas por los diputados del NPD no se contuviese de hecho ninguna consigna explícitamente política. 
te $-\mathrm{o}$, de apreciarse éste, su gravedad— de que fueran exhibidos en pasillos o despachos individuales, y menos todavía en cafeterías o bibliotecas, dependencias todas ellas que forman parte usual de nuestros legislativos pero en las que no se verifican debates ni votaciones, en donde la exhibición de estos signos carece de potencial perturbador, y en las que por lo tanto deberían reducirse al mínimo las excepciones al régimen general de libertades.

Por la misma regla, quizás también debería tolerarse su exhibición cuando ésta se verificase desde la propia tribuna de oradores por un diputado que reglamentariamente estuviera en el uso de la palabra, y durante el lapso de tiempo en el que estuviera haciendo uso de ésta, toda vez que en tal ocasión tampoco cabría argumentar que el debate pudiera resultar interrumpido o perturbado, ni que al parlamentario aludido pudiera generársele indefensión, ya que siempre tendría a su alcance la solicitud de un turno de palabra por alusiones. La exhibición en tal caso de estos lemas o signos se podría asimilar sin mucho esfuerzo a la que a menudo llevan a cabo los parlamentarios que deciden complementar sus argumentos con la exhibición ante los demás miembros de las cámaras y los medios de comunicación de fotografías, gráficos, documentos o titulares de prensa, más o menos legibles, práctica ésta que resulta no solo usual, sino también pacíficamente admitida.

\section{A LA ESPERA DE CONCLUSIONES, UN DEBATE ABIERTO}

El debate ha quedado, en todo caso, abierto. En marcado contraste con la tolerancia - e incluso la indisimulada connivencia - reinante hasta ahora en la mayor parte de nuestros legislativos respecto de la exhibición de consignas y símbolos por parte de los parlamentarios en el ejercicio de sus funciones representativas, las decisiones adoptadas por la Presidencia de Les Corts Valencianes en mayo de 2009 y febrero de 2012, y su posterior iniciativa para regular normativamente la cuestión de una manera tan clara como restrictiva, ponen sobre la mesa la existencia de dos diferentes actitudes respecto la cuestión que nos ocupa: una, más consolidada, partidaria a la vez de maximizar el alcance de la libertad de actuación de los parlamentarios, y de obviar toda regulación al respecto; y otra, más novedosa, partidaria por un lado de regular con toda la claridad posible la cuestión, y por otro de abordarla de manera que se priorice el mantenimiento del orden en el recinto parlamentario y el normal desarrollo de los trabajos de la cámara.

El hecho de que esta nueva actitud ante la cuestión haya sido objeto de aplicación no ya en una, sino en dos ocasiones, de que haya sido posteriormente 
normativizada, y de que además cuente con ejemplos concurrentes en otros sistemas parlamentarios de inequívoca impronta democrática, podría muy bien servir de precedente para un cambio de actitud en otras asambleas parlamentarias - para empezar, en nuestro Congreso de los Diputados- que hasta la fecha han preferido apostar por la flexibilidad y la discreción. Más aun: el hecho de que el caso haya sido sometido a la consideración del Tribunal Constitucional español dota al mismo de una — ahora ya indiscutible — trascendencia constitucional, al tiempo que a la posible sentencia del alto Tribunal de una también indiscutible trascendencia política. En caso de desestimar el recurso por no apreciar en él vulneración alguna de derechos, el Constitucional brindaría a los presidentes de nuestras cámaras legislativas un buen incentivo para adoptar sin miedo medidas más contundentes cuando en el futuro se repitan incidentes como los que sin ánimo de exhaustividad hemos enumerado en los primeros párrafos de este trabajo; mientras que si su decisión fuera la de tomar en consideración y estimar el recurso, con toda probabilidad los límites de lo tolerable en nuestros hemiciclos quedarían automáticamente ampliados.

A lo que en cambio resulta más difícil dar respuesta es cuál de las dos posibilidades - la de dar un espaldarazo a la flexibilidad, o la de brindar argumentos para la firmeza - serviría para incrementar la eficacia de nuestras asambleas y la capacidad de sus integrantes para hallar consensos. Que es, al fin y al cabo, de lo que se trata.

Title:

FREEDOM OF SPEECH AND PARLIAMENTARY PROCEDURE: CAN A PARLIAMENTARY SPEECH TAKE THE FORM OF A T-SHIRT, A STICKER, OR A BANNER?

\section{Summary:}

1. Introduction: On the reiteration and the relevance of the display of messages and signs of political content in the parliamentary chamber. 2. The rights at stake. 3. The case of the valencian legislative. 4. A critical appraisal. 5. While waiting for conclusions, an open debate.

\section{Resumen:}

¿Asistir a una sesión parlamentaria luciendo sobre la ropa un mensaje político claramente legible, es una manifestación de la libertad de expresión, o una interferencia inaceptable en el desarrollo de los debates parlamentarios, susceptible de alterar el orden en la cámara? ¿Debe permitirse que un miembro del Parlamento exprese su opinión 
en el hemiciclo luciendo pegatinas o adhesivos, mostrando octavillas, o desplegando pancartas?

La reiteración de estos comportamientos, cada vez más habituales en nuestra vida parlamentaria, viene desde hace tiempo exigiendo del Derecho Parlamentario una respuesta que sea al mismo tiempo acorde con los principios de un Estado democrático, compatible con el fluido funcionamiento de una de sus más importantes instituciones, y susceptible de ser aplicada de manera coherente en nuestros diferentes legislativos. En el presente artículo se aventura por primera vez, y a partir del análisis de varios casos recientes, esta posible solución.

\section{Abstract:}

To attend a parliamentary sitting wearing clothes featuring a clearly readable political message, is a kind of manifestation of the freedom of speech, or an unacceptable interference in the development of the parliamentary debates, likely to alter the order in the house? Is it acceptable for a Member of Parliament to express his or her opinion within the hemicycle wearing pins o stickers, showing flyers or deploying banners?

The reiteration of these behavior, increasingly common in our parliamentary life, has been demanding from Parliamentary Law an answer that is at the same time consistent with the principles of a democratic State, compatible with the fluid operation of one of its most important institutions, and suitable of being applied in a consistent manner in our different legislatures. In this article we propose for the first time, and on the basis of an analysis of several recent cases, this possible solution.

\section{Palabras clave:}

parlamento, reglamento parlamentario, libertad de expresión, poderes de policía.

\section{Key words:}

parliament, Standing Orders, freedom of speech, police powers. 
